\title{
A QUALIDADE EM SERVIÇOS NO CONTEXTO DA COMPETITIVIDADE
}

\section{SERVICE QUALITY IN THE CONTEXT OF COMPETITIVITY}

\author{
André Luís Policani Freitas, D.Sc. \\ Professor Associado \\ Universidade Estadual do Norte Fluminense (UENF) \\ Laboratório de Engenharia de Produção - Centro de Ciência e Tecnologia \\ Avenida Alberto Lamego, 2000 - Campos dos Goytacazes/RJ CEP 28013-602 \\ (22) 2726-1632 Ramal 222- policani@uenf.br
}

\section{RESUMO}

Desde a década de 80, a busca pela Excelência em Serviços e o interesse pela mensuração da qualidade de serviços têm se caracterizado como uma importante estratégia utilizada pelas organizações para obter a vantagem competitiva. A literatura científica sobre este assunto até os tempos atuais é rica e diversificada, apesar de alguns aspectos ainda gerarem contradições entre os pesquisadores. Neste contexto, este trabalho se propõe a abordar conceitos e aspectos tradicionalmente empregados no âmbito da qualidade em serviços, destacando técnicas e metodologias que buscam a Excelência em Serviços e a mensuração da qualidade em serviços.

Palavras-chave: qualidade em serviços, metodologias, consumidor.

\begin{abstract}
Since the 80's, the pursuit for Excellence in Services and the interest in measurement of Service Quality have been characterized as an important strategy adopted by companies to obtain the competitive advantage. Up to nowadays, the scientific literature about this subject is very much rich and diversified, even though some aspects are still contradictory to the researchers. In this context, this work proposes to approach concepts and aspects traditionally used in the Service Quality field, highlighting techniques and methodologies which search for Excellence in Services and the measurement of Service Quality.
\end{abstract}

Key-words : service quality, methodologies, customer. 


\section{INTRODUÇÃO}

Por muitos anos, até o início da década de $60^{1}$, a ordem econômica mundial foi caracterizada por grande produtividade. Durante este período, como a demanda por produtos geralmente era superior à oferta, tudo o que se produzia podia ser vendido (BOLWIJIN E KUMPE, 1990, p.44).

Entretanto, ao longo dos anos, o mercado começou a se tornar mais competitivo. Neste período, o fator preço tornou-se o principal diferencial competitivo. Em busca da eficiência produtiva, muitas organizações passaram a empregar os princípios Tayloristas e Fordistas de produção, buscando reduzir custos através da produção em massa de poucos modelos de produtos. Estes princípios envolveram o estudo dos tempos e movimentos, a divisão do trabalho em tarefas simples, a limitação de linhas de produtos, dentre outros (WOMACK ET AL, 1992, p.31).

No fim dos anos 60, diante do aumento da freqüência de ocorrência de falhas e defeitos nos produtos, os consumidores se tornaram mais críticos em relação a estes, passando a avaliar não somente o preço, mas também a qualidade. Este comportamento foi fortemente influenciado pela participação de indústrias japonesas no mercado. Estas indústrias utilizavam o sistema de produção enxuta ${ }^{2}$, que possibilitava a fabricação de produtos de alta qualidade a preços reduzidos.

Em meados da década de 70, os consumidores estavam mais conscientes da moda e interessados em produtos com linhas e concepções mais modernas, porém consumiam de maneira imprevisível. Muitas indústrias ficaram sobrecarregadas devido à produção de vários

\footnotetext{
1 É importante ressaltar que as datas que delimitam as etapas da história da industrialização não são absolutamente precisas, pois os diversos setores industriais tiveram processos de evolução distintos. Em geral, observa-se que grande parte da literatura científica referencia-se ao processo de evolução da indústria automobilística para delimitar estas etapas.

${ }^{2}$ A produção enxuta (expressão definida pelo pesquisador John Krafcik, do IMVP) é "enxuta" por utilizar menor quantidade de tudo em comparação com a produção em massa: força de trabalho, espaço para fabricação, investimento em ferramentas, etc. (WOMACK ET AL, 1992, p.3).
} 
modelos, aos altos custos de logística e ao surgimento de grandes estoques de produtos acabados e de produtos que se tornavam obsoletos.

Ainda nesta fase, a competitividade entre as empresas passou a ser fundamentada em termos do trinômio Produtividade $x$ Qualidade $x$ Flexibilidade. A figura 1 ilustra este trinômio.

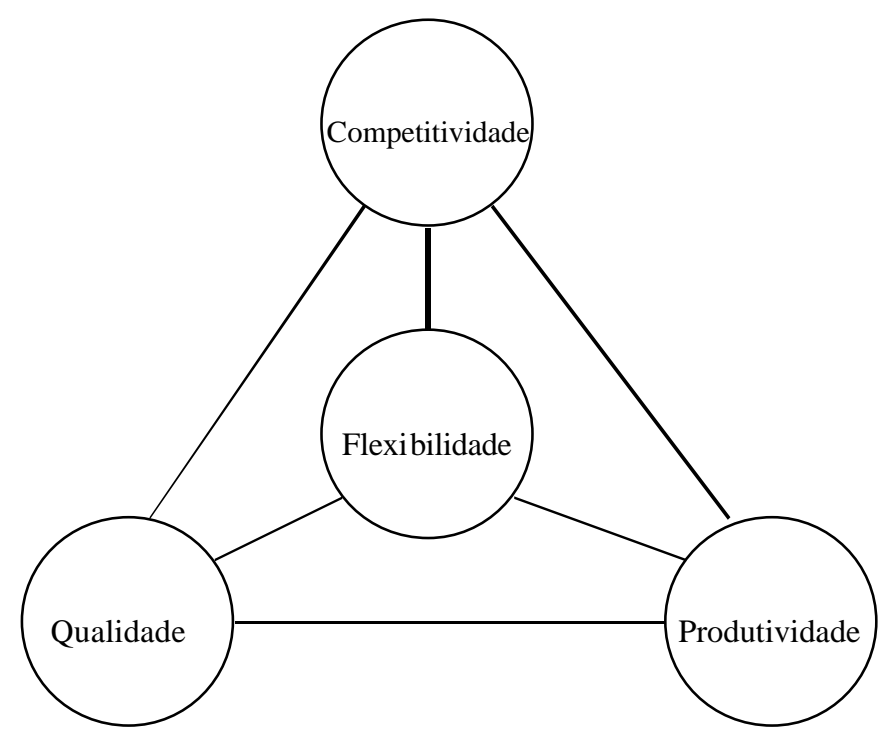

Figura 1: O trinômio Produtividade x Qualidade x Flexibilidade

A partir de então, além de oferecer preço e qualidade em seus produtos, as organizações deveriam ser flexíveis o suficiente para:

- desenvolver/produzir novos produtos mais rapidamente que os concorrentes;

- ajustar a produção e o controle de estoques, evitando oscilações entre a falta de produtos no mercado e o excesso de produtos em estoque, e;

- adaptar os processos de produção rapidamente frente às novas tendências do mercado.

Dentre as ações empregadas para aumentar a flexibilidade das empresas citam-se: a redução do tempo de set up das máquinas, o estabelecimento do fluxo contínuo de produção, projetos envolvendo menor número de componentes, o desenvolvimento de CAD/CAM, o aperfeiçoamento da tecnologia da informação, etc. 
Entretanto, observa-se que a partir do início da década de 80, as organizações de serviço vêm representando uma parcela cada vez maior e mais importante no cenário econômico mundial (FREITAS, 2001, p.10). Neste contexto, estas organizações buscam continuamente atingir a Excelência em Serviços, considerando os clientes como peça fundamental para a conquista e manutenção dos mercados.

Em geral, administradores, gerentes e pesquisadores buscam identificar, dentre outros aspectos: os critérios que melhor definem a qualidade de um serviço particular, os critérios que são mais importantes e que os que geram mais satisfação (insatisfação) do cliente; o relacionamento entre a qualidade dos serviços e o grau de satisfação do cliente; o impacto da qualidade do serviço e satisfação do cliente nas intenções de consumo do serviço (CRONIN \& TAYLOR, 1992, p.55)

Neste contexto, este trabalho se propõe a abordar conceitos e aspectos tradicionalmente utilizados no âmbito da Qualidade em Serviços, destacando as técnicas e metodologias que buscam a Excelência em Serviços e a mensuração da qualidade em serviços.

\section{ASPECTOS DA QUALIDADE DE SERVIÇOS}

Definir precisamente o real significado de "serviços" vem sendo uma difícil tarefa para os pesquisadores que atuam na área da qualidade. De forma a auxiliar na compreensão deste significado, diversos autores têm identificado características pertinentes aos serviços ${ }^{3}$. Neste contexto, Parasuraman et al (1988, p.13) destacam três pontos como características dos serviços:

- $\quad$ simultaneidade : serviços são consumidos quase que simultaneamente ao momento em que são produzidos, tornando difícil ou quase impossível detectar e corrigir as falhas antes que elas ocorram e afetem o cliente.

\footnotetext{
${ }^{3}$ Neste artigo considera-se produto como sendo produto tangível e serviço como sendo produto intangível.
} 
- intangibilidade : os serviços representam um produto não físico, ou seja, não podendo ser transportados e/ou armazenados;

- heterogeneidade: a grande variedade de serviços existentes e o forte relacionamento com o fator humano dificultam a atividade de padronização e estimação de preços. Curiosamente, de acordo com o serviço que está adquirindo, o cliente poderá receber diversas denominações, dentre as quais: consumidor, freguês, usuário, hóspede, paciente, requisitante, etc.

Outro aspecto importante é que em algumas situações o resultado de um serviço é difícil de ser previsto. Entretanto, nota-se que atualmente os consumidores estão consultando pessoas que já tenham experimentado um serviço/produto específico, antes de adquiri-lo. Nestas circunstâncias é importante notar que os clientes não avaliam somente os aspectos tangíveis de um produto/serviço, mas também os aspectos intangíveis a ele agregados.

Vale ainda destacar que a prestação de serviços não é restrita apenas ao momento da venda, mas engloba também atividades de pós-venda como manutenção e assistência técnica, dentre outras. Ou seja: mais crítico em relação à qualidade dos produtos e serviços oferecidos, o cliente vem desejando algo mais do que a qualidade do produto e do atendimento no momento da compra. Neste ponto de vista, o produto deverá continuar funcionando perfeitamente após a venda durante o prazo previsto para tal (vida útil) e isso somente será possível com serviços pós-venda devidamente executados.

Em resposta a este cenário de competição, muitas organizações têm buscado superar as necessidades e expectativas dos clientes - estas organizações procuram várias formas de superar a concorrência e garantir a fidelidade dos clientes em relação aos seus produtos e serviços. Entretanto, observa-se que a qualidade dos serviços prestados ainda deixa a desejar em muitos aspectos. 
Segundo Albrecht (1998, p.15), a apatia, a frieza, a inflexibilidade, no atendimento, o desrespeito ao prazo de entrega, os preços elevados, a demora e a desorganização no atendimento são algumas das queixas comuns dos clientes em relação aos serviços. Dentre as situações tipicamente relatadas pelos clientes pode-se citar:

(i) ao contactar uma organização (pessoalmente, por telefone, etc.), o cliente deseja ser atendido da maneira mais rápida e eficaz possível. Entretanto, com freqüência nota-se que, seja por despreparo ou má vontade do funcionário, o cliente percorre vários setores da organização, recebe informações desencontradas, sem ter o seu problema resolvido.

(ii) muitas vezes o cliente busca informações junto a funcionários da limpeza ou da segurança de uma organização. Esta situação ocorre principalmente após o cliente receber um mau atendimento de um recepcionista, ou quando este não encontra um funcionário da organização disponível para prestar-lhe as informações desejadas.

(iii) nos bancos, nota-se que muitos clientes ainda preferem realizar as operações financeiras com os atendentes (“caixas”) a realizá-las nos terminais eletrônicos. Um dos principais motivos para este comportamento é a inabilidade/receio de utilizar os recursos da tecnologia de informação (exclusão digital).

Essas e muitas outras situações similares estão presentes tanto nas organizações privadas quanto nas públicas. Particularmente, esta afirmação contraria o mito, até pouco tempo difundido, de que a má qualidade em serviços somente era característica de organizações públicas. Neste contexto, pode-se constatar que algumas organizações públicas que se tornaram privadas estão fornecendo serviços com qualidade bem inferior aos anteriormente prestados.

No sentido de evitar ou eliminar a existência de problemas desta natureza, é fundamental que as organizações possuam uma estrutura de gerenciamento direcionada para a Qualidade de Serviços. 


\section{GERENCIAMENTO PARA A QUALIDADE DE SERVIÇOS}

À medida que a competição entre as organizações aumenta, o cliente torna-se cada vez mais exigente e crítico em relação aos serviços prestados. Ou seja, os padrões de qualidade de atendimento estabelecidos pelo mercado estão cada vez mais severos.

Na tentativa de evitar que serviços sejam fornecidos com má qualidade, Parasuraman et al (1985, p.49) sugerem cinco procedimentos que devem ser implementados pelas organizações:

- desenvolver instrumentos de pesquisa para entender as reais necessidades e expectativas (explícitas e implícitas) dos clientes;

- transformar as necessidades e expectativas do consumidor em projetos de serviço que possam realmente atendê-los;

- transformar o projeto em especificações adequadas de serviço ou padrões que possam ser implementados (nesta etapa, o benchmarking ${ }^{4}$ é uma técnica recomendada);

- $\quad$ prestar os serviços em conformidade com as especificações estabelecidas; e

- não criar expectativas que não possam ser atendidas ou cumpridas (gap entre as expectativas do cliente e o atual serviço fornecido).

Devido às características intrínsecas aos serviços, um modelo de gerenciamento visando a excelência em serviços pode ser composto por três elementos fortemente relacionados, no qual o cliente é considerado como peça fundamental para o sucesso empresarial. Segundo Albrecht (1998, p.32), tais elementos são:

(i) Foco do serviço: consiste nos procedimentos e ações que devem ser planejados e implementados para que retratem os reais desejos e necessidades do cliente.

\footnotetext{
${ }^{4}$ Técnica que consiste na comparação dos índices de uma organização com os melhores índices do mercado, objetivando que esta organização se torne a melhor em seu ramo através do aperfeiçoamento contínuo da qualidade (CAMPOS, 1994, p.21).
} 
(ii) Funcionários: são todas as pessoas pertencentes à organização que, uma vez conhecido o foco do serviço, devem estar preparados para realizá-los.

(iii) Suporte técnico: neste aspecto estão englobados sistemas, técnicas e procedimentos que auxiliam a prestação dos serviços.

Destes elementos, nota-se que o elemento humano é considerado como fator primordial na prestação de serviços. Mais especificamente, na rotina de trabalho, administradores e gerentes não são capazes de presenciar todas as ações dos funcionários. Nesses momentos, tais funcionários são os reais administradores e representantes a organização. Neste contexto, algumas condições devem ser observadas para obtenção da excelência no atendimento:

(i) periodicamente é necessária a mensuração do grau de satisfação dos funcionários e clientes em relação aos serviços prestados. Compartilhada com a coleta de sugestões e reclamações, esta atividade pode ser capaz de identificar pontos de deficiência no serviço ou que desagradam aos clientes.

(ii) através do treinamento adequado, do recebimento de remuneração adequada e desempenhando funções nas quais possuam habilidade e competência, os funcionários se tornarão mais motivados e comprometidos com a qualidade;

(iii) a organização deve estar estruturada de forma que todos os funcionários tenham conhecimento da sua estrutura funcional e suas atribuições, além de ter conhecimento dos produtos/serviços oferecidos;

(iv) os funcionários devem tentar solucionar os problemas no local e no momento em que ocorrem ou então encaminhá-los ao profissional capacitado, fornecendo informações corretas. Este procedimento evita a propagação das reclamações, que podem gerar uma imagem ruim da organização e causar perdas de vendas. 
(v) os funcionários devem ser capazes de se adaptar ao perfil de cada cliente, definindo o nível de formalidade adequada à situação (BARROS, 1998b, p. 56). Por exemplo, nos instantes que antecedem a uma cirurgia, uma "pequena dose" de descontração do enfermeiro/médico é capaz de reduzir o estado de tensão do paciente. Por outro lado, ressalta-se que uma "dose exagerada" de descontração pode causar uma imagem de displicência e irresponsabilidade.

Entretanto, para que o gerenciamento em serviços proporcione melhorias contínuas nos padrões de qualidade de serviços, é necessário que exista um processo bem estruturado para solução de problemas - processo este que deve ser compreendido por todas as pessoas envolvidas (COBRA E RANGEL, 1993, p.68). Em linhas gerais, este processo pode ser composto pelas etapas ilustradas na figura 2.

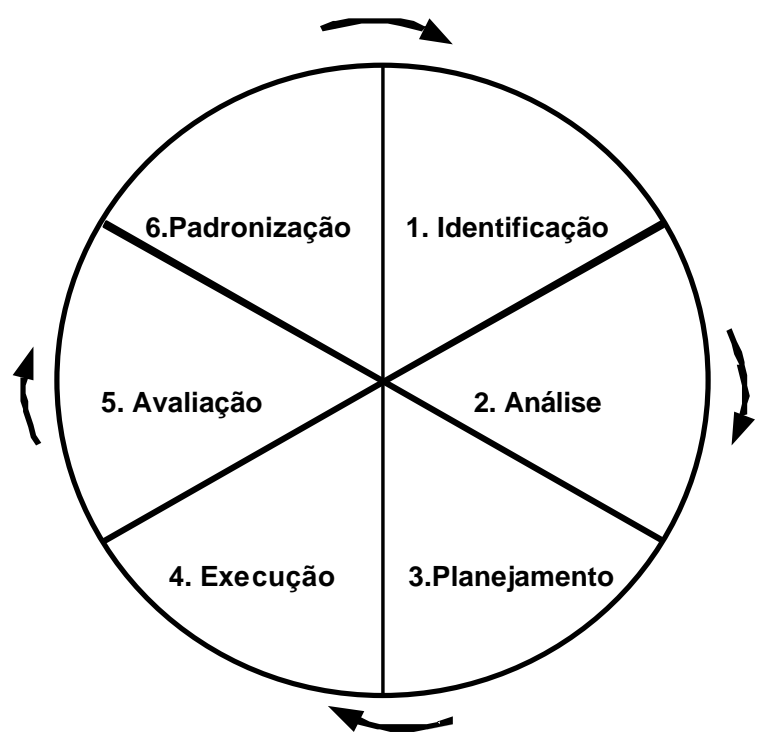

Figura 2: Processo para melhoria da qualidade em serviços.

Fonte: Freitas (2001, p.15).

- Identificação: nesta etapa são definidos os problemas e/ou oportunidades de melhorias, visando aumentar a satisfação do cliente. Dentre estes, devem ser priorizados os que causam maior impacto ao cliente e os que são mais rápidos e fáceis de serem resolvidos. 
- Análise: através da análise baseada em dados e fatos sobre os problemas e oportunidades selecionados, busca-se determinar as causas destes problemas e avaliar os seus efeitos sobre as melhorias desejadas.

- Planejamento: nesta etapa são relacionadas ações potenciais para solucionar as causas da origem dos problemas ou uma lista de ações para aumentar a satisfação do cliente. Tais ações devem ser avaliadas quanto ao risco, ao custo e aos recursos necessários para a melhoria da qualidade e também quanto a possíveis efeitos colaterais de cada ação selecionada.

- Execução: nesta etapa as ações planejadas devem ser implementadas conforme os procedimentos previamente estabelecidos.

- Avaliação: através da avaliação ou monitoramento das ações que foram implementadas é possível verificar se estas realmente estão sendo eficazes na solução dos problemas ou nas melhorias desejadas.

- Padronização: caso as ações implementadas estejam realmente sendo eficazes, estas devem ser padronizadas, de tal forma que os problemas ocorridos não venham mais ocorrer e que os clientes permaneçam satisfeitos. Caso contrário, o problema ainda persiste e deve ser solucio nado.

Diversas metodologias e estratégias vêm sendo desenvolvidas buscando aprimorar os fatores considerados determinantes na modernização e no aumento da competitividade das organizações. Em geral, tais metodologias e estratégias destinam-se a proporcionar a melhoria contínua da qualidade de serviços, e a avaliar a qualidade de serviços. Entretanto, para uma melhor compreensão destas metodologias, é necessário definir Determinantes e Indicadores de Qualidade. 


\section{DETERMINANTES E INDICADORES DE QUALIDADE}

No processo de monitoramento e avaliação da qualidade, os serviços geralmente são descritos em função de Critérios ou Determinantes da Qualidade, que representam os subconjuntos das possíveis dimensões pelas quais o serviço pode ser descrito. Os elementos de cada subconjunto são denominados Indicadores de Qualidade (IQ).

Mais precisamente, o uso destes indicadores tem como finalidade principal a verificação da qualidade na execução de atividades e processos empregados na produção de produtos e serviços, ou seja, avaliar se realmente existem melhorias significativas em relação aos padrões de referência.

Para a utilização eficiente dos indicadores, deve-se conhecer o real significado de cada indicador e como utilizá-lo corretamente. Neste sentido, quando se considera rapidez no atendimento como indicador, deve-se observar que a rapidez está relacionada com o tempo com que leva para o pedido ser feito e o tempo para que este seja concretizado. Entretanto, a rapidez por si só não significa qualidade - esta deverá estar relacionada com a eficácia do serviço.

A definição dos indicadores de qualidade de serviços tem sido objeto de interesse de muitos pesquisadores. Por exemplo, Parasuraman et al. (1988, p. 23) definiram a escala SERVQUAL que estabelece cinco dimensões da qualidade: tangíveis, confiabilidade, segurança, presteza e empatia. Embora tais dimensões cubram uma grande variedade de serviços, estas devem ser definidas de acordo com as necessidades de cada organização e com o tipo de serviço.

Neste contexto, vale destacar o emprego de indicadores de qualidade subjetivos. Tais indicadores estão intimamente relacionados com a avaliação da qualidade de serviços através da captação do grau de satisfação dos clientes. Cortesia, credibilidade e segurança são exemplos destes indicadores. 
Em geral, os indicadores de qualidade objetivos são empregados na avaliação e controle de atividades e processos. Dentre os indicadores de qualidade objetivos usuais, citam-se: tempo de execução de atividades ou processos, números de falhas cometidas, tempo de espera, número de reclamações, número de clientes perdidos (e de novos clientes). Estes indicadores permitem que as atividades e processos sejam controlados mediante ao cumprimento de procedimentos previamente estabelecidos, sem que haja uma mudança brusca e repentina nos processos até então executados.

Uma vez estabelecidos os critérios e indicadores da qualidade, estes devem ser adequadamente agrupados em algum instrumento para avaliação dos serviços. Na próxima seção apresentam-se alguns dos instrumentos usualmente utilizados.

\section{INSTRUMENTOS PARA MENSURAÇÃO DA SATISFAÇÃO}

A captação de informações dos clientes consiste em uma das etapas de maior importância no processo de avaliação da qualidade de serviços. Esta etapa deve ser realizada através do emprego de um instrumento de medição eficaz e preciso, pois caso contrário, as informações obtidas podem não ser representativas da sua percepção (HAYES, 1992, p.4).

Segundo Vavra (1998, p.9), “a pesquisa de satisfação do cliente é muito diferente da pesquisa de marketing ou da medição da opinião pública - o principal elemento de diferenciação encontra-se na insistência de que o público pesquisado se mantenha no anonimato. Os clientes não querem necessariamente permanecer no anonimato, ao contrário, o não retorno do resultado das pesquisas e das reclamações podem deixá-los frustrados e concluir que as organizações não se importam com suas opiniões e sugestões". Os meios de pesquisa mais utilizados para este fim são: 
- Formulários de pesquisa (questionários) - podem ser fornecidos junto com os produtos, deixados sobre um balcão ao alcance do cliente ou enviados pelo correio (MIRSHAWKA, 1993, p.270).

- Entrevistas - realizadas pessoalmente ou por telefone, são capazes de captar informações importantes dos clientes, mas a qualidade das informações depende muito da habilidade do entrevistador e da duração da entrevista.

- Urna de sugestões - é um instrumento de comunicação diária com os clientes, sendo muito útil devido a sua capacidade de captar sugestões de melhorias e reclamações.

- Pesquisa de mercado: usualmente é realizada por institutos de pesquisa independentes, com custos elevados. É utilizada para o desenvolvimento e lançamento de novos produtos/serviços, podendo também ser utilizada para medir e avaliar os desempenhos dos produtos de uma organização e de seus concorrentes (COBRA E RANGEL, 1993, p.109).

- Serviço de Atendimento ao Consumidor (SAC) - consiste de uma linha telefônica (ou e-mail) disponibilizada para o cliente, com o objetivo de captar a ocorrência de problemas, registrando-a para que providências sejam tomadas. Buscam também a captar sugestões, opiniões e reações do consumidor em relação ao lançamento de novos produtos e desempenho de novos serviços.

- Mesa redonda com o cliente - Segundo Barros (1998a, p.37), esta técnica consiste numa reunião planejada com um pequeno grupo de clientes selecionados aleatoriamente. É recomendável que os trabalhos sejam conduzidos por um consultor externo a fim de estimular os clientes a expressarem espontaneamente, de maneira imparcial e irrestrita, seus desejos, críticas e sugestões de melhorias. Tais informações são encaminhadas aos setores da organização para julgamento, adoção, ajuste ou até mesmo rejeição justificada. 
Além de captar o grau de importância e satisfação do cliente em relação aos serviços fornecidos pela organização, é recomendável que a atividade de pesquisa busque averiguar com o cliente se já ocorreu algum problema com o produto ou na prestação do serviço, como foi dada a assistência, se ele pretende comprar novamente da organização ou se a recomendaria para outras pessoas.

Um outro aspecto relevante no processo da mensuração da satisfação diz respeito à veracidade dos resultados. Se não houver comprometimento com a qualidade, funcionários cujos serviços foram avaliados podem apresentar apenas os julgamentos positivos e favoráveis.

\section{METODOLOGIAS OU TÉCNICAS PARA MELHORIA DOS SERVIÇOS}

Estas metodologias devem ser empregadas a partir do momento que um processo de prestação do serviço já está projetado de forma a atender às necessidades dos clientes. Tais metodologias visam aperfeiçoar o desempenho da organização em pontos críticos especificados. Dentre as metodologias para tal fim, citam-se:

- QFD (Quality Function Deployment): nesta metodologia, coletam-se informações dos clientes para identificar quais são as necessidades (exigências) em relação ao serviço, a importância de cada necessidade e as características técnicas necessárias ao serviço. Em seguida, são construídas Matrizes de Planejamento, através das quais deve-se estabelecer relações entre as exigências e as características técnicas, avaliações dos serviços em relação às características técnicas, avaliação das interações entre as características técnicas. Estas matrizes identificam as principais áreas/ações a serem enfocadas para a obtenção de serviços com melhor qualidade (JEONG \& OH, 1998, p.377). 
- Ciclos de Serviços: ao receber um serviço, o cliente passa por uma seqüência de Momentos da Verdade, denominada de Ciclo de Serviço. Cada Momento da Verdade representa o instante em que o cliente entra em contato com qualquer aspecto da organização (funcionários, instalações, tele/fax, etc.) e, de acordo com esse contato, ele pode formar sua opinião a respeito da qualidade do serviço (ALBRECHT, 1998, p.36). (Vide figura 3). Assim, através do entendimento deste ciclo e dos momentos da verdade, eventuais falhas ocorridas podem ser mais facilmente identificadas e, mediante a tomada de ações corretivas/preventivas, estas podem ser evitadas de forma a proporcionar um serviço de melhor qualidade.

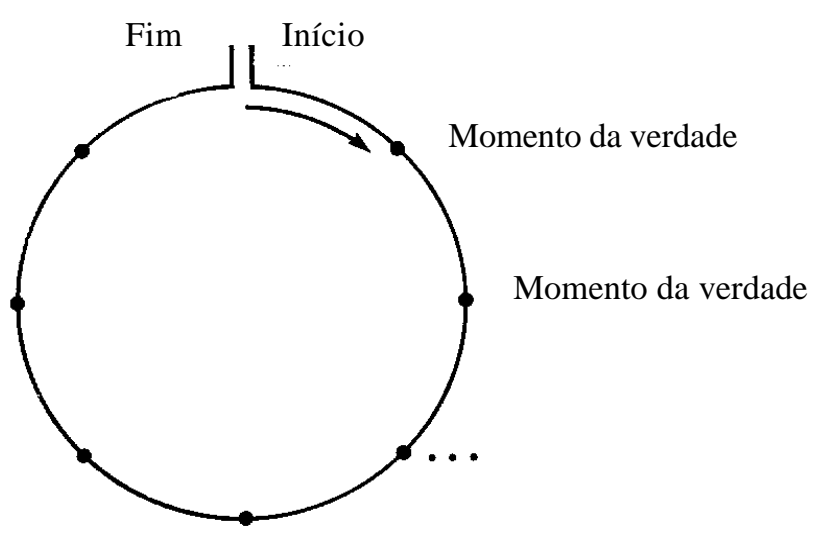

Figura 3: O Ciclo de Serviço

Fonte: Albrecht (1998, p.36)

- Linha de visibilidade: representa o limite que separa o que acontece à vista do consumidor do que acontece "nos bastidores" da prestação de serviços. Expressivos resultados têm sido obtidos quando se permite que os clientes tenham conhecimento da execução de tarefas que antes não conheciam. Além de aumentar a dimensão da qualidade relacionada com a confiabilidade do serviço, a prática deste método também reduz a percepção do tempo de espera (HARVEY, 1998, p.592). No Brasil, observa-se esta prática em padarias e restaurantes. 
- Garantia de serviço: constitui-se basicamente de ações retificadoras a serem tomadas pela organização prestadora de serviços caso haja alguma irregularidade ou imprevisto na realização do serviço. Segundo Hart (1988, p.59), "esta técnica é uma importante fonte de marketing e de ações operacionais, pois informa aos consumidores os benefícios dos serviços oferecidos e informa aos funcionários quais são os resultados que eles devem produzir. Além disto, esta técnica permite reconhecer explicitamente as falhas dos serviços (situações onde os consumidores não encontram os resultados prometidos)".

- Cliente oculto: esta técnica visa fazer com que os prestadores de serviços vejam os seus serviços de forma semelhante à visão dos clientes (HARVEY, 1998, p.594). Existem duas variantes principais:

(i) quando profissionais simulam ser clientes, avaliam os serviços de acordo com critérios predefinidos e elaboram um check list que descreve os eventuais desvios;

(ii) quando clientes reais são treinados a fazer observações a respeito dos serviços que costumam solicitar regularmente.

Caso o anonimato do profissional seja mantido durante a simulação, os dados obtidos são representativos da percepção real do consumidor. No entanto, se os empregados perceberem que estão sendo avaliados, podem criar uma situação de desconforto ou podem se esforçar além do normal para servir ao cliente.

- Recuperação: as ações de recuperação visam corrigir eventuais falhas junto ao cliente, buscando aliviar ao máximo as conseqüências destas e informando ao cliente a respeito destas ações. A manutenção da informação ao cliente, especialmente quando a recuperação é lenta e cansativa, é uma etapa crítica. Segundo Berry et al. (1994, p.34), “a recuperação da qualidade do serviço somente será bem sucedida se as expectativas do cliente forem atingidas". 
Uma prática desta metodologia é conhecida como Recall, na qual uma organização comunica aos seus clientes a respeito da ocorrência de alguma falha em algum de seus produtos/serviços. Um exemplo deste procedimento ocorre na indústria automobilística: uma montadora detecta um falha em determinado de lote de produção (em geral, as falhas podem ocorrer nas seguintes etapas: projeto, fabricação ou montagem) e convoca os proprietários para comparecerem a uma de suas concessionárias a fim de solucionar o problema.

\section{A AVALIAÇÃO E CLASSIFICAÇÃO DA QUALIDADE DE SERVIÇOS}

A avaliação da qualidade de serviços constitui-se numa atividade de extrema importância para que uma empresa seja competitiva - apesar de muitas vezes existirem dificuldades devido à ausência de padrões de qualidade suficientemente objetivos e precisos. Adicionalmente, vale ressaltar que, apesar de diversos estudos preliminares já terem sido realizados abordando o problema em questão, a qualidade de serviços ainda é um objeto de difícil compreensão, definição e entendimento, existindo afinidades e contrariedades entre os pesquisadores (vide o anexo A);

Diversas metodologias foram desenvolvidas para avaliar a qualidade dos serviços. Entretanto, observa-se que ainda existe uma carência no tratamento de problemas desta natureza, principalmente no que diz respeito à subjetividade e imprecisões inerentes ao processo de julgamento. Em geral, estes problemas são caracterizados por julgamentos subjetivos envolvendo variáveis não tradicionalmente mensuráveis (variáveis qualitativas/subjetivas), onde imprecisões, hesitações e incertezas são incorporadas e ampliadas quando realizadas por múltiplos avaliadores.

Apesar da existência destas metodologias, existem situações em que, além de avaliar um serviço " $X$ " à luz de um conjunto de dimensões da qualidade (critérios), deve-se atribuir o desempenho deste serviço a uma das categorias pré-definidas (problema de classificação). 
Especificamente no contexto das metodologias de auxílio à tomada de decisão sob múltiplos critérios, o problema de classificação da qualidade dos serviços é um problema de decisório em que um conjunto de avaliadores $\underline{\boldsymbol{A}}=\left\{A_{1}, A_{2}, \ldots, A_{m}\right\}$, além de avaliar um serviço " $X$ " genérico à luz de um conjunto $\underline{\boldsymbol{F}}=\left\{g_{1}, g_{2}, \ldots, g_{n}\right\}$ de dimensões da qualidade (critérios), devem também atribuir o desempenho deste serviço a uma das categorias pré-estabelecidas.

Estas categorias são limitadas por fronteiras compostas de elementos cujos valores dependem da escala de julgamento utilizada. No âmbito da avaliação da qualidade, usualmente os desempenhos dos serviços avaliados são representados em termos padrões de desempenhos em forma de "estrelas" (utilizadas na classificação da categoria de hotéis, restaurantes, etc.) e também segundo padrões alfabéticos (utilizada até recentemente na avaliação de cursos de pós-graduação pela CAPES e, atualmente, na avaliação dos cursos de graduação pelo MEC) (FREITAS, 2001, p.35). A figura 4 ilustra este problema.

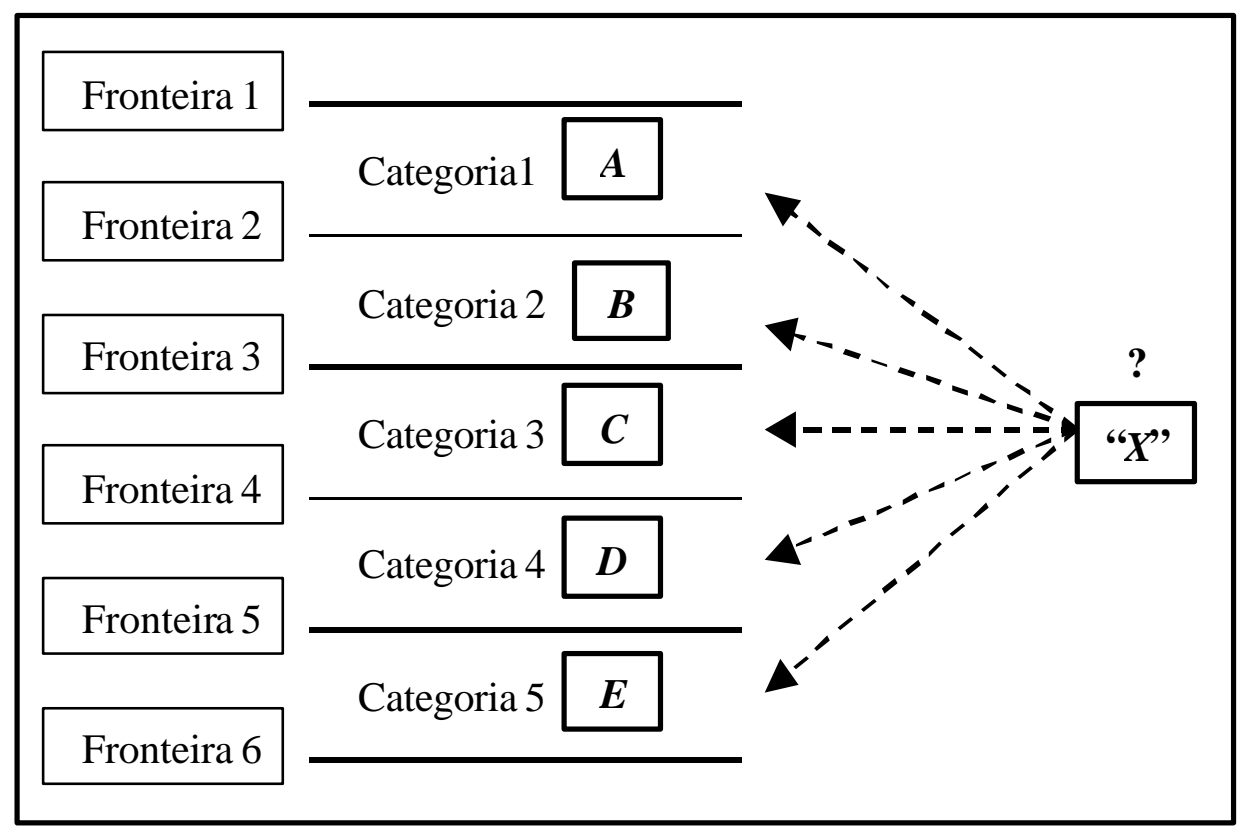

Figura 4: Classificação do serviço " $X$ " segundo padrões alfabéticos

Fonte: Freitas (2001, p.27) 
Um dos procedimentos mais empregados para avaliar e classificar a qualidade dos serviços é através da mensuração do Grau de Satisfação dos avaliadores (clientes, funcionários ou avaliadores externos) com o desempenho do serviço à luz de um conjunto de critérios considerados relevantes - o que caracteriza um problema de decisão multicritério envolvendo múltiplos avaliadores/decisores. A figura 5 ilustra esquematicamente este problema.

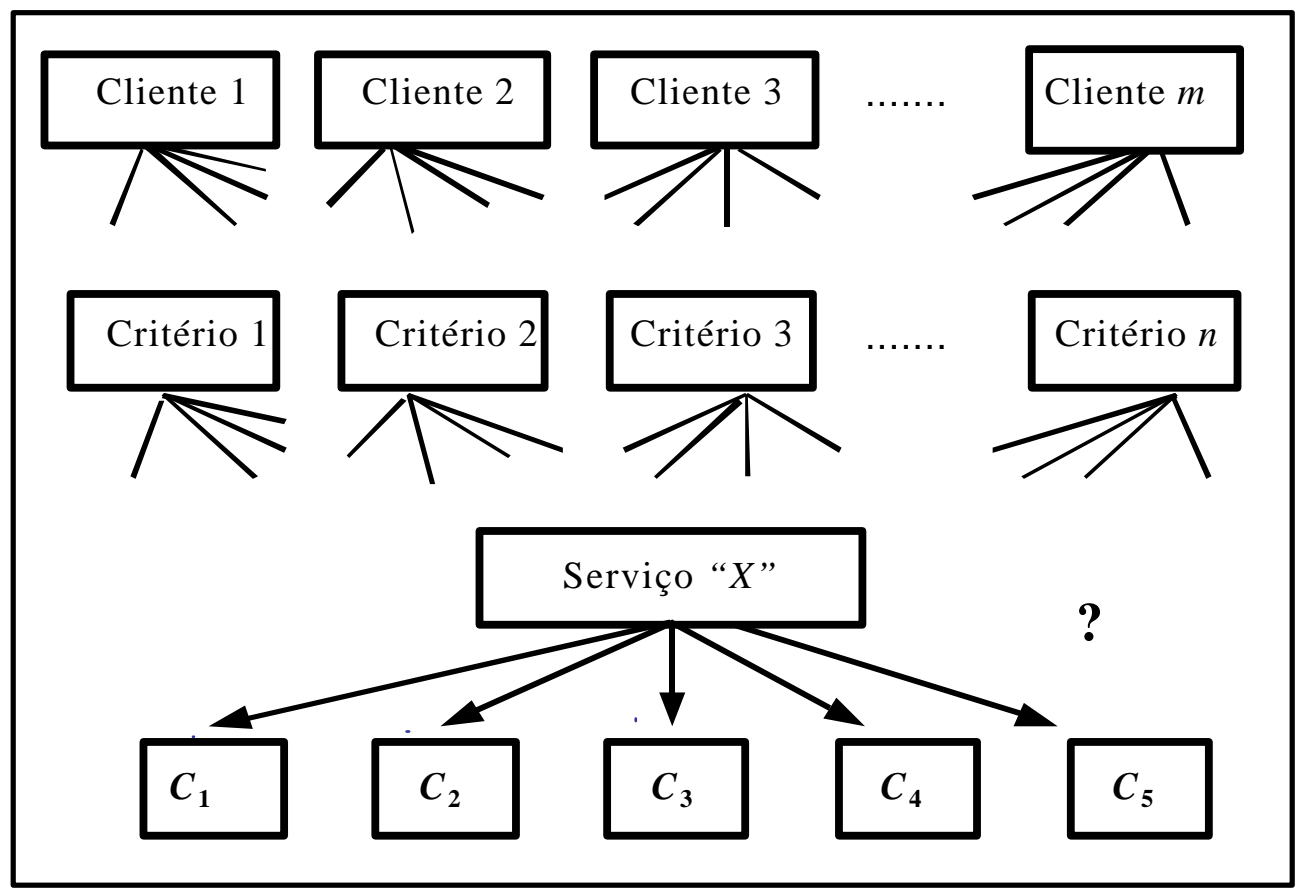

Figura 5: Decisão multicritério com múltiplos avaliadores

Fonte: Freitas (2003, p.37)

Nesta situação, o desempenho do serviço " $X$ " será classificado, conforme os julgamentos de cada avaliador (cliente). Em geral, existe um conflito entre as classificações obtidas a partir de diferentes avaliadores. Segundo Freitas e Costa (2003, p.2), neste caso, a análise pode seguir três vertentes: 
(i) buscar um consenso entre os avaliadores a respeito da classificação do desempenho do serviço;

(ii) estabelecer um procedimento para agregar os julgamentos de todos os clientes em uma única classificação final; ou,

(iii) identificar e analisar o comportamento dos subgrupos compostos por avaliadores (clientes) que apresentam opiniões semelhantes a respeito do serviço.

Uma das maiores dificuldades encontradas em problemas desta natureza consiste em estabelecer um procedimento ou regras de decisão precisas que permitam obter o consenso entre avaliadores/decisores. Esta tarefa em geral não é fácil, principalmente devido à existência de diversos parâmetros a serem definidos, tais como: os critérios mais relevantes ao problema, a importância destes critérios segundo diversos avaliadores, os limites de preferência, os limites de corte, etc. (GRECO ET AL, 2001, p.3). Além disso, acrescenta-se a este aspecto a natureza subjetiva e intrínseca ao processo de julgamento do serviço à luz dos diversos critérios especificados.

No contexto do tratamento da subjetividade, das imprecisões e incertezas intrínsecas aos processos decisórios, metodologias fundamentadas na Análise Multicritério à Decisão (AMD) e em teorias correlatas (Teoria dos Conjuntos Aproximativos, a Lógica Fuzzy, a Análise da Envoltória de Dados, dentre outras) continuam sendo desenvolvidas. Entretanto, a maior parte destas dedica-se ao tratamento de problemas envolvendo um único avaliador/decisor. Este fato revela que ainda existe uma carência de ferramentas científicas que permitam o tratamento de problemas decisórios com múltiplos avaliadores/decisores. Em especial, a modelagem e o tratamento desta categoria de problemas ainda representam um grande desafio para os especialistas em análise decisória. 


\section{CONSIDERAÇÕES FINAIS}

Apesar de muito abordado em pesquisas científicas, o tema "Qualidade em Serviços" ainda é objeto de muitas discussões entre pesquisadores, gerentes e administradores. Em sua essência, este questionamento é decorrente do envolvimento de dois objetos de entendimento não tão trivial: qualidade e serviços.

Clientes finais do serviço (clientes externos) assim como os funcionários da empresa (clientes internos) constituem-se elementos importantes para medição e avaliação do serviço fornecido. Particularmente, os funcionários da organização são as pessoas mais capacitadas para detectar a "qualidade percebida" pelo cliente resultante dos Momentos da Verdade. Ou seja, eles são mais capazes de detectar se um determinado serviço não é bem recebido pelo cliente ou não é bem executado.

Apesar da existência de diversas metodologias que buscam avaliar a qualidade de serviços, observa-se que:

(i) existe uma tendência de se avaliar a qualidade de serviços em função da mensuração da satisfação dos clientes com o desempenho do serviço, e

(ii) ainda existe uma carência no tratamento de problemas desta natureza. Esta carência retrata principalmente a questão das imprecisões e incertezas intrínsecas ao processo de julgamento dos Graus de Importância dos critérios e dos Graus de Satisfação dos clientes com o desempenho do serviço.

Com o intuito de eliminar/reduzir esta carência e também contribuir para a Excelência em Serviços, considera-se fundamental o desenvolvimento de metodologias de análise decisória destinadas à avaliação/classificação da qualidade em serviços, que sejam capazes de incorporar múltiplos determinantes (critérios) da qualidade e também comportem julgamentos de múltiplos avaliadores. 


\section{REFERÊNCIAS}

ALBRECHT, Karl. Revolução nos serviços - como as empresas podem revolucionar a maneira de tratar os seus clientes, 5. ${ }^{\mathrm{a}}$ ed. Editora Pioneira, 256p., 1998.

BARROS, C.D.C. A Arte de Ouvir é Essencial, Banas - Controle de Qualidade, São Paulo, pp 37, 1998a.

1998b.

, Encante para Ter Fidelidade, Banas - Controle de Qualidade, São Paulo, pp 56,

BERRY, L.L., PARASURAMAN, A., ZEITHAML, V.A. Improving service quality in America: lessons learned. The Academy of Management Executive. Vol. 8, p. 32-58, 1994.

BOLTON, R.N., DREW, J.H. A longitudinal analysis of the impact of service changes on customer attitudes, Journal of Marketing, v. 55, pp.1-9, 1991a.

, Amultistage model of customer's assesments of service quality and value, Journal of Consumer Research, v. 17, pp.375-384, 1991b.

BOLWIJN P.T., KUMPE, T. Manufacturing in the 1990's - productivity, flexibility and innovation, Long Range Planning, vol 23, nº 4, pp. 44-57, UK, 1990.

CAMPOS, V.F. TQC - Controle da Qualidade Total (no estilo japonês), 5. ${ }^{\text {a }}$ edição, Belo Horizonte: Editora QFCO, 229p, 1994.

COBRA, M., RANGEL, A. Serviços ao Cliente - Uma Estratégia Competitiva, $2^{\text {a }}$ edição, São Paulo: Editora Marcos Cobra., 1993.

CRONIN, J.J., TAYLOR, S.A. Measuring service quality: a reexamination and extension, Journal of Marketing, v.56, pp. 55-68, 1992.

FREITAS, A.L.P., COSTA, H. G, Uma Análise Multicritério para a Classificação da Qualidade de Serviços Utilizando o Método ELECTRE TRI, Anais do XXIII ENEGEP Encontro Nacional de Engenharia de Produção, Ouro Preto/MG, 2003.

FREITAS, A. L. P., Uma Metodologia Multicritério de Subordinação para a Classificação da Qualidade de Serviços sob a Ótica do Cliente, Tese de Doutorado - Programa de PósGraduação em Ciências de Engenharia - UENF, jul 2001.

GRECO ET AL, "Rough Sets Theory For Multicriteria Decision Analysis", European Journal of Operational Research, n. ${ }^{\circ}$ 129, pp. 1 - 47, 2001. 
HART, C. W. The Power of Unconditional Service Guarantees, Harvard Business Review, n. ${ }^{\circ}$ 66, pp. 54-62, 1998.

HARVEY, J. Service Quality: A Tutorial, Journal of Operations Management, n. ${ }^{\circ}$ 16, pp. 583-597, 1998.

HAYES, B.E. Measuring Customer Satisfaction - Development and Use of Questionnaires, ASQC, 1992.

JEONG, M., OH, H. Quality Function Deployment: an extended framework for service quality and customer satisfaction in the hospitality industry, Hospitality Management, ${ }^{\circ}{ }^{\circ} 17$, pp. 375-390, 1998.

MIRSHAWKA, V. Criando Valor Para o Cliente, Makron Books do Brasil Editora Ltda, 1993.

OLIVER, R.L. A cognitive model of the antecedents and consequences of satisfaction decisions, Journal of Marketing Research, n. ${ }^{\circ}$ 17, pp.460-469, 1980.

PARASURAMAN, A., ZEITHAML, V.A., BERRY, L.L. SERVQUAL: a multiple-item scale for measuring consumer perceptions of service quality, Journal of Retailing, vol. 64, $\mathrm{n}^{\mathrm{o}}$ 1, pp. 12-40, 1988.

A conceptual model of service quality and its implications for future research, Journal of Marketing, pp.41-50, 1985.

RUST, R.T. ET AL. What you don't know about customer-perceived quality: the role of customer expectation distributions, Marketing Science, vol. 18, nº 1, pp. 77-92, 1999.

VAVRA, T.G. Seus clientes estão satisfeitos? Tradução de Jacqueline A. Brandão. São Paulo: Banas-Controle de Qualidade, pp. 8-12, 1998.

WOMACK, J.P., JONES, D.T., ROOS, D. A Máquina que Mudou o Mundo, Editora Campus, 1992. 


\section{ANEXO A: ALGUMAS DEFINIÇÕES PARA QUALIDADE DE SERVIÇOS}

\begin{tabular}{|c|c|}
\hline Estudos & Forma de avaliação da qualidade de serviços \\
\hline $\begin{array}{l}\text { SERVQUAL } \\
\text { Parasuraman et al. } \\
\text { (1988) }\end{array}$ & $\begin{array}{l}\text { A diferença entre as expectativas dos consumidores sobre o desempenho } \\
\text { de um serviço e suas estimações do atual desempenho de organização de } \\
\text { serviço fornece a percepção da qualidade de serviços. }\end{array}$ \\
\hline $\begin{array}{l}\text { Bolton e Drew } \\
\qquad \text { (1991a) }\end{array}$ & $\begin{array}{l}\text { A qualidade de serviços é análoga a uma atitude de forma a sugerir que } \\
\text { satisfação é um antecedente da qualidade de serviços. A qualidade } \\
\text { percebida dos serviços (Attitude })_{t} \text { é uma função da percepção residual do } \\
\text { consumidor a respeito da qualidade dos serviços de um período anterior } \\
\text { (Attitude } t-1) \text { e o seu nível de satisfação (ou insatisfação) com o atual } \\
\text { nível de desempenho do serviço }\left(C S / D_{t}\right) \text {. Esta noção pode ser } \\
\text { equacionada da seguinte forma: Attitude } t=g\left(C S / D_{t}, \text { Attitude }_{t-1}\right) \text {. }\end{array}$ \\
\hline $\begin{array}{l}\text { Bolton \& Drew } \\
\qquad(1991 b)\end{array}$ & $\begin{array}{l}\text { A qualidade de serviço é uma função do nível de satisfação (ou } \\
\text { insatisfação) do consumidor com o atual nível de desempenho do serviço } \\
\left(C S / D_{t}\right) \text { e da não confirmação de suas expectativas (disconfirmation). } \\
\text { Qualidade de Serviço }=\mathrm{q}_{0}\left(\mathrm{CS} / \mathrm{D}_{\mathrm{t}} \text {, não confirmação). }\right.\end{array}$ \\
\hline Oliver (1980) & $\begin{array}{l}\text { A qualidade de serviço é uma forma de atitude. A atitude }(\mathrm{Att}) \text { é } \\
\text { inicialmente uma função das expectativas (Exp): }\left[\mathrm{Att}_{\mathrm{t} 1}=\mathrm{f}(\operatorname{Exp})\right] \text {. } \\
\text { Posteriormente, a atitude é uma função da atitude anterior e o atual nível } \\
\text { de satisfação com o produto ou serviço }(\mathrm{Sat}):\left[\mathrm{Att}_{\mathrm{t} 2}=\mathrm{f}\left(\mathrm{Att}_{\mathrm{t} 1}, \mathrm{Sat}_{\mathrm{t} 2}\right)\right] \text {. }\end{array}$ \\
\hline $\begin{array}{l}\text { SERVPERF } \\
\text { Cronin \& Taylor } \\
\text { (1992) }\end{array}$ & $\begin{array}{l}\text { Qualidade de serviços = estimação do consumidor a respeito do atual } \\
\text { desempenho de uma organização de serviço. }\end{array}$ \\
\hline
\end{tabular}

